\title{
Managing dyslipidemia in HIVIAIDS patients: challenges and solutions
}

\author{
This article was published in the following Dove Press journal: \\ HIVIAIDS - Research and Palliative Care \\ 17 December 2014 \\ Number of times this article has been viewed
}

\author{
Nazik Elmalaika OS Husain' \\ Mohamed H Ahmed ${ }^{2}$ \\ 'Department of Pathology, Faculty \\ of Medicine and Health Sciences, \\ Omdurman Islamic University, \\ Khartoum, Sudan; ${ }^{2}$ Department of \\ Medicine, Milton Keynes Hospital, NHS \\ Foundation Trust, Milton Keynes, UK
}

\begin{abstract}
Human immunodeficiency virus (HIV) is a chronic disease associated with dyslipidemia and insulin resistance. In addition, the administration of combination antiretroviral therapy is associated with an increase in the incidence of metabolic risk factors (insulin resistance, lipoatrophy, dyslipidemia, and abnormalities of fat distribution in HIV patients). HIV dyslipidemia is a common problem, and associated with an increase in incidence of cardiovascular disease. Further challenges in the management of HIV dyslipidemia are the presence of diabetes and metabolic syndrome, nonalcoholic fatty liver disease, hypothyroidism, chronic kidney disease, the risk of diabetes associated with statin administration, age and ethnicity, and early menopause in females. Dyslipidemia in patients with HIV is different from the normal population, due to the fact that HIV increases insulin resistance and HIV treatment not only may induce dyslipidemia but also may interact with lipid-lowering medication. The use of all statins (apart from simvastatin and lovastatin) is safe and effective in HIV dyslipidemia, and the addition of ezetimibe, fenofibrate, fish oil, and niacin can be used in statin-unresponsive HIV dyslipidemia. The management of dyslipidemia and cardiovascular disease risks associated with HIV is complex, and a certain number of patients may require management in specialist clinics run by specialist physicians in lipid disorders. Future research is needed to address best strategies in the management of hyperlipidemia with HIV infection.
\end{abstract}

Keywords: HIV, dylipidaemia, cardiovascular disease, insulin resistance, fatty liver, lipid lowering medication

\section{Introduction}

Human immunodeficiency virus (HIV) is a chronic disease associated with increased mortality and morbidity from HIV-related conditions. ${ }^{1}$ Furthermore, HIV is associated with dyslipidemia in the form of high triglycerides and low high-density lipoprotein (HDL). ${ }^{2}$ The possible mechanisms for HIV-induced dyslipidemia are increased cytokine levels (TNF and IL-6), decreased lipid clearance, and increased hepatic synthesis of very low-density lipoprotein (VLDL). ${ }^{2}$ Furthermore, Lo and Grinspoon suggested that there is an independent HIV effect on cardiovascular risk. ${ }^{3}$ Moreover, the administration of combination antiretroviral therapy (cART) is associated with an increase in the incidence of metabolic risk factors (insulin resistance, lipoatrophy, dyslipidemia, and abnormalities of fat distribution) in HIV patients. ${ }^{2,4}$ In a multicenter cross-sectional study of elderly individuals with HIV, dyslipidemia was found in 54\%, cardiovascular disease (CVD) in 23\%, and lipodystrophy in 58\%. ${ }^{5}$ Hejazi et al found that dyslipidemia is common in HIV subjects receiving antiretroviral medication: it reaches (82.3\%) among 1,583 patients in their Malaysian study. ${ }^{6}$

It is important to recognize that as patients live longer, they became vulnerable to many complications, prominently CVD. The dyslipidemia associated with cART
Correspondence: Mohamed H Ahmed Department of Medicine, Milton Keynes Hospital, NHS Foundation Trust, Standing Way, Eaglestone, Milton Keynes, Buckinghamshire MK6 5LD, UK Email elziber@yahoo.com (c) (1) (5) 2015 Husain and Ahmed. This work is published by Dove Medical Press Limited, and licensed under Creative Commons Attribution - Non Commercial (unported, v3.0) BY LC License. The full terms of the License are available at http://creativecommons.org/licenses/by-nc/3.0/. Non-commercial uses of the work are permitted without any further hew to how to request permission may be found at: http://www.dovepress.com/permissions.php 
administration is typically manifested as decreased HDL cholesterol (HDL-C), increased LDL-C (including small, dense LDL), and increased total cholesterol. Such values are associated with increased cardiovascular risk in persons who are not HIV-infected, and obviously place HIV patients at risk for premature cardiovascular events. Common medications used in the treatment of HIV are protease inhibitors (PIs), nucleoside reverse-transcriptase inhibitors (NRTIs), and nonnucleoside reverse-transcriptase inhibitors (NNRTIs). ${ }^{7,8}$ HIV-related dyslipidemia is increasingly recognized as a problem in patients on cART, particularly those on PI-based regimes. ${ }^{9}$ PIs are associated with an incidence of dyslipidemia in $70 \%$ and $80 \%$ in the form of high triglycerides and LDL-C and decreased HDL-C and accumulation of ApoE and ApoC III. PIs are also associated with central obesity, lipoatrophy, and insulin resistance. ${ }^{10}$ The effect of PIs in lipid profile is due to inhibition of lipogenesis, adipocyte differentiation, decrease in hepatocyte clearance of hepatic chylomicron and VLDL, and stimulation of hepatic synthesis of triglycerides. ${ }^{10,11}$

NRTIs are also associated with high triglycerides and lipoatrophy, but this effect is less seen with administration of tenofovir. It is recommended to switch to tenofovir in case dyslipidemia becomes an issue, especially in children. ${ }^{12}$ It is worth mentioning that abacavir and didanosine (NRTIs) were associated with independent risk of myocardial infarction in the DAD study. ${ }^{13}$ Interestingly, the use of NNRTIs like nevirapine protected against low HDL-C levels, while the use of efavirenz was associated with increase in total cholesterol and triglycerides. ${ }^{14}$ Penzak et al suggested that an increased percentage of death attributable to cardiac, renal, and hepatic disease among HIV patients treated with highly active antiretroviral therapy (ART). ${ }^{15}$ The extensive use of cART medication in HIV patients is associated with dyslipidemia, insulin resistance and diabetes. ${ }^{16}$ The aim of this article is to review the current challenges in treating dyslipidemia with HIV and recommend the solutions from the evidence available so far.

\section{Why is dyslipidemia in HIV patients a challenge to manage? \\ Cardiovascular risk and HIV disease}

Major cardiovascular-related comorbidities are prevalent in HIV/acquired immunodeficiency syndrome (AIDS), especially older and obese individuals. Chu et al found prevalence rates of $26 \%, 48 \%$, and $13 \%$ for hypertension, dyslipidemia, and diabetes, respectively. They thought that because cardiovascular risk is modifiable, effective treatment of related comorbidities may improve morbidity and mortality in HIV-infected patients. ${ }^{17}$

Dyslipidemia is also increasingly recognized in HIVinfected children. ${ }^{18}$ HIV-infected children may be at risk for premature CVD, as they have high levels of cholesterol and triglycerides. ${ }^{19}$ Even perinatally HIV-infected adolescents may be susceptible to aggregate atherosclerotic CVD risk. ${ }^{20}$ Interestingly, the prevalence of coronary heart disease (CHD) among a Mediterranean cohort of 3,760 HIV-infected patients was low: 81 patients (prevalence 2.15\%). ${ }^{21}$ Table 1 has a summary of some studies showing association between HIV and CVD. ${ }^{22-25}$

\section{Diabetes mellitus, metabolic syndrome, and HIV}

Dyslipidemia and increased blood glucose are the most common health threats, with a high incidence among HIV/AIDS patients on ART worldwide. Dyslipidemia, lipodystrophy, and diabetes mellitus can result from long-term ART in HIV patients. In their cohort study, Menezes de Pádua and Moura obtained information on long-term adverse drug reactions to ART from medical charts of treatment-naïve HIV-infected adult patients initiating ART. Of 233 medical charts, 26.1\% contained at least one long-term adverse reaction, corresponding to 45 cases of dyslipidemia (19.3\%), 16 (6.9\%) of lipodystrophy, and five of diabetes mellitus (2.1\%). ${ }^{26}$ Studies from Ghana, Tanzania, Thailand, Ethiopia, and Brazil showed an increase in prevalence of lipoatrophy, insulin resistance, and diabetes in particular with ART. ${ }^{27-31}$

Dyslipidemia significantly increases with cumulative exposure to ART. Tripathi et al found that there was a significantly higher risk of dyslipidemia in their ART-treated HIVinfected group (adjusted hazard ratio 1.18, 95\% confidence interval [CI] 1.07-1.30) and a significantly lower risk in the ART-naïve HIV-infected group (adjusted hazard ratio 0.66, 95\% CI 0.53-0.82) compared to the control non-HIV-infected group. They also found that preexisting hypertension, obesity, and diabetes increased the risk of dyslipidemia, whereas hepatitis $\mathrm{C}$ virus, lower $\mathrm{CD}^{+}$T-cell count, and higher HIV viral load had a protective effect. ${ }^{32}$ Furthermore, Ledergerber et al suggested that current treatment with PI- and NRTI-containing regimens was associated with the risk of developing type 2 diabetes mellitus. ${ }^{33}$

HIV represents a chronic inflammatory condition, and this may lead to insulin resistance. Furthermore, changes in body configuration (central obesity, truncal obesity, and lipoatrophy) and associated dyslipidemia all accelerate the process that lead to diabetes mellitus with HIV and ART. 
Table I Summary of some studies showing association between HIV and CVD

\begin{tabular}{|c|c|c|c|}
\hline Type of study & Description of the study & Main outcome & Reference \\
\hline $\begin{array}{l}\text { Prospective observational } \\
\text { study: Data Collection on } \\
\text { Adverse Events of Anti-HIV } \\
\text { Drugs (DAD Study) }\end{array}$ & $\begin{array}{l}\text { Investigation of the impact of } \\
\text { diabetes and preexisting CHD } \\
\text { on the development of a new } \\
\mathrm{CHD} \text { episode among } 33,347 \\
\text { HIV-infected individuals }\end{array}$ & $\begin{array}{l}\text { The rate of CHD episodes was } 7.52 \text { times higher in those } \\
\text { with preexisting CHD than in those without preexisting } \\
\text { CHD, but it was only } 2.41 \text { times higher in those with } \\
\text { preexisting DM compared with those without DM. }\end{array}$ & 22 \\
\hline $\begin{array}{l}\text { Prospective } \\
\text { observational study }\end{array}$ & Data from the DAD Study & $\begin{array}{l}\text { Increase in prevalence of metabolic syndrome from } \\
19.4 \% \text { in } 2000-2001 \text { to } 41.6 \% \text { in } 2006-2007 \text {. }\end{array}$ & 23 \\
\hline Cohort study & $\begin{array}{l}\text { Health care system-based } \\
\text { cohort study using a large data } \\
\text { registry with } 3,85 \mathrm{I} \text { HIV and } \\
\text { I,044,589 non-HIV patients }\end{array}$ & $\begin{array}{l}\text { Acute myocardial infarction rates were increased in HIV } \\
\text { versus non-HIV patients, particularly among women. The HIV } \\
\text { cohort had significantly higher proportions of hypertension, } \\
\text { diabetes, and dyslipidemia than the non-HIV cohort. }\end{array}$ & 24 \\
\hline $\begin{array}{l}\text { Prospective } \\
\text { observational study }\end{array}$ & $\begin{array}{l}\text { Data from } 23,437 \text { patients } \\
\text { infected with the human } \\
\text { immunodeficiency virus }\end{array}$ & $\begin{array}{l}\text { The incidence of myocardial infarction increased from } \\
\text { I.53 per I,000 person-years in those not exposed to protease } \\
\text { inhibitors to } 6.01 \text { per I,000 person-years in those exposed } \\
\text { to protease inhibitors for more than } 6 \text { years. The relative } \\
\text { rate of myocardial infarction per year of protease-inhibitor } \\
\text { exposure was } 1.16 \text {, whereas the relative rate per year of } \\
\text { exposure to nonnucleoside reverse-transcriptase inhibitors } \\
\text { was } 1.05 \text {. Increased exposure to protease inhibitors is } \\
\text { associated with an increased risk of myocardial infarction, } \\
\text { which is partly explained by dyslipidemia. }\end{array}$ & 25 \\
\hline
\end{tabular}

Abbreviations: HIV, human immunodeficiency virus; CVD, cardiovascular disease; CHD, coronary heart disease; DM, diabetes mellitus.

HIV-associated lipodystrophy syndrome consists of lipoatrophy, lipohypertrophy, and metabolic disturbances (dyslipidemia and hyperglycemia). Lipoatrophy involves the face, lower limbs, and buttocks. It is closely related to NRTIs and rarely associated with PIs. Lipohypertrophy is related to the accumulation of adipose tissue (abdomen, breast, and interscapular fat), and this is likely due to PIs. Central fat accumulation is observed more in females, and is associated with increased body fat. Furthermore, PIs are also associated with dyslipidemia due to mitochondrial toxicity and inhibition of glucose transporter type 4, and this leads to inhibition of adipocyte differentiation and an increase in triglyceride levels and insulin resistance. NRTIs can also be associated with dyslipidemia and insulin resistance. ${ }^{34}$ Other mechanisms were suggested to contribute towards development of HIV-associated lipodystrophy syndrome, some of which are inflammation, inhibition of lipid metabolism (inhibition of lipoprotein lipase and excess triglyceride and risk of insulin resistance), oxidative stress and impaired function of adipokines and transcript factors (adiponectin, leptin, sterol regulatory binding proteins (SREBPs) and peroxisomal proliferatory activator receptors (PPAR) $\alpha$ and $\gamma^{35}$

\section{Nonalcoholic fatty liver disease and HIV}

HIV and ART are associated with nonalcoholic fatty liver disease (NAFLD). ${ }^{36-38}$ The significance of NAFLD lies in the fact that it is associated with insulin resistance in $95 \%$ of cases and is also associated with a high risk of CVD and dyslipidemia. ${ }^{39,40}$ Price et al showed in a multicenter study that computed tomography-defined NAFLD is common among men at risk for HIV infection, is associated with greater visceral adiposity and insulin resistance, and prolonged exposure to dideoxynucleoside analogs is associated with higher prevalence. ${ }^{41}$ The prevalence of NAFLD in Asian patients with HIV is estimated to be around $31 \%$, and is associated with high BMI, dyslipidemia, and high aspartate transaminase:alanine transaminase ratio, but not with HIVrelated factors (treatment with dideoxynucleoside analogs [didanosine, stavudine, and zalcitabine] and cumulative duration of ART). ${ }^{42}$ Sterling et al showed that NAFLD is around $26 \%$, and the only clinical or laboratory feature associated with biopsy-proven steatosis was $\gamma$-glutamyl transpeptidase and insulin resistance. ${ }^{43}$ NAFLD is also seen in HIV patients who are coinfected with hepatitis C. ${ }^{44,45}$ The only effective therapy for NAFLD is weight loss, and the use of statins with NAFLD appears to be safe and effective.

\section{Statins and associated risk of diabetes in diabetogenic conditions like HIV}

Statins are used worldwide in the treatment of hyperlipidemia and CVD in HIV patients. The association between diabetes and statin treatment has been observed in several studies. In a collaborative meta-analysis of randomized 
clinical trials, statin therapy was associated with a slightly increased risk of development of diabetes, but the risk was low, both in absolute terms and when compared with the reduction in coronary events, and statins can be prescribed for individuals with moderate or high cardiovascular risk or existing CVD. ${ }^{46}$ Furthermore, intensive-dose statin therapy was associated with an increased risk of new-onset diabetes compared with moderate-dose statin therapy in a metaanalysis of five statin trials. ${ }^{47}$ Data from the Women's Health Initiative study (161,808 postmenopausal women aged 50-79 years) showed that statin-medication use in postmenopausal women is associated with an increased risk for diabetes. ${ }^{48}$ Interesting reviews on the subject have recently been published by Athyros and Mikhailidis ${ }^{49}$ and Athyros et al. ${ }^{50}$ It is not clear whether the risk of incident diabetes associated with the administration of statins will increase the risk of further insulin resistance associated with HIV and ART. It is worth mentioning that it is recommended clinical practice to continue to monitor plasma glucose in HIV patients taking statin therapy. Further studies are needed to assess whether statin administration in individuals with HIV carries a high risk for diabetes.

\section{High prevalence of chronic kidney disease among HIV patients and associated dyslipidemia}

HIV patients are at risk of developing chronic kidney disease (CKD). Several studies suggested that the slight deterioration in renal function is likely due to the HIV more than the ART. In Taiwan, the prevalence of CKD in HIV-infected patients was low (7.03\%), and diabetes, hypertension, and hypercholesterolemia were demonstrated to be associated with CKD. ${ }^{51}$ In a Danish study, tenofovir and indinavir reduced estimated glomerular filtration rate (eGFR), while time with HIV only had a modest effect on renal function. ${ }^{52}$ The most common causes of acute kidney injury in HIV-infected persons are systemic infections and adverse drug effects. The prevalence of CKD is rising in the HIV-infected population, and CKD is increasingly likely to be caused by comorbid conditions, such as diabetes and hypertension, which frequently cause CKD

Table 2 Summary of the effect of different statins and other lipid-lowering medications

\begin{tabular}{|c|c|c|}
\hline Lipid-lowering medication & Main recommendation & References \\
\hline Simvastatin and lovastatin & $\begin{array}{l}\text { The HIV Medicine Association of the Infectious Disease Society of America and the Adult AIDS } \\
\text { Clinical Trial Group recommended that simvastatin and lovastatin should not be given to patients } \\
\text { taking Pls or delavirdine. This was also endorsed by the International AIDS Society USA Panel, } \\
\text { which recommended that concomitant use of lovastatin or simvastatin with protease inhibitors } \\
\text { or HAART is contraindicated. }\end{array}$ & $74-80$ \\
\hline Atorvastatin & $\begin{array}{l}\text { The HIV Medicine Association of the Infectious Disease Society of America and the Adult AIDS Clinical } \\
\text { Trial Group and International AIDS Society USA panel advised that atorvastatin is recommended } \\
\text { as a first-line agent for high LDL-C, with a starting dose of atorvastatin } 10 \mathrm{mg} \text { once daily. Caution is } \\
\text { needed when combined with fenofibrate. In certain conditions, administration of atorvastatin } \\
\text { (with clarithromycin and lopinavir/ritonavir, delavirdine) was associated with rhabdomyolysis. }\end{array}$ & $|5| 7,,8 \mid$ \\
\hline Pravastatin & $\begin{array}{l}\text { Pravastatin is recommended as first line in the management of HIV dyslipidemia. Interestingly, } \\
\text { the combination therapy with fenofibrate and pravastatin for HIV-related dyslipidemia provides } \\
\text { substantial improvements in lipid parameters and appears safe. The International AIDS Society } \\
\text { USA panel recommended pravastatin and atorvastatin as first-line agents. }\end{array}$ & $82-85$ \\
\hline Rosuvastatin & $\begin{array}{l}\text { Rosuvastatin is not metabolized by CYP3A4 and is eliminated through feces. Interestingly, } \\
\text { rosuvastatin } 10 \mathrm{mg} / \text { day was more effective than pravastatin } 40 \mathrm{mg} / \text { day on LDL-C and triglyceride } \\
\text { levels in HIV-I-infected patients receiving a boosted protease inhibitor. Interestingly, rosuvastatin } \\
\text { and atorvastatin are preferable to pravastatin, due to greater declines in total cholesterol, } \\
\text { LDL-C, and non-HDL-C. }\end{array}$ & $86-91$ \\
\hline Fluvastatin & $\begin{array}{l}\text { The recommendations of the HIV Association of the Infectious Disease Society of America } \\
\text { and Adult AIDS Clinical Trials Group, were that fluvastatin was a reasonable alternative } \\
\text { to atorvastatin and pravastatin for patients on protease inhibitors. }\end{array}$ & $78,92,93$ \\
\hline Ezetimibe & $\begin{array}{l}\text { Ezetimibe as monotherapy is an effective and safe lipid-lowering medication in HIV dyslipidemia, } \\
\text { and also can be used in those with poor response to statin. In addition, the combination of statin } \\
\text { and ezetimibe is also effective and safe lipid lowering medication in HIV-dyslipidaemia. }\end{array}$ & $94-99$ \\
\hline Fenofibrate & $\begin{array}{l}\text { Fenofibrate is a generally safe and useful agent for the treatment of mixed dyslipidemia } \\
\text { and hypertriglyceridemia in people with HIV infection. The combination of pravastatin, fish oil, } \\
\text { and niacin with fenofibrate appears to be safe and effective. }\end{array}$ & $85,100-107$ \\
\hline Niacin & In two studies, niacin was effective and safe in improving lipid profile in HIV patients. & $108-110$ \\
\hline
\end{tabular}

Abbreviations: Pls, protease inhibitors; HAART, highly active antiretroviral therapy; LDL-C, low-density lipid cholesterol; HIV, human immunodeficiency virus; CYP3A4, cytochrome P450 3A4; HDL-C, high-density lipid cholesterol; AIDS, acquired immunodeficiency syndrome. 
in the general population. ${ }^{53}$ In rural northern KwaZulu-Natal, South Africa, Madala et al conducted a cross-sectional study of 302 patients, 290 (96\%) of whom were black African, to assess whether diabetes and HIV are associated with CKD. Mean age \pm standard deviation was $47.1 \pm 17.0$ years. ${ }^{54}$ Approximately $86.4 \%$ of females and $54.5 \%$ of males were overweight/obese. Dyslipidemia was observed in $47.9 \%$ females and $29.2 \%$ males $(P<0.001)$. They found that the eGFR was $<30 \mathrm{~mL} / \mathrm{min} / 1.73 \mathrm{~m}^{2}$ in $50.6 \%$ of patients. Using logistic regression analysis, they observed the following CKD risk factors: hypertension (77.8\%), diabetes (29.8\%), HIV (28.5\%), glomerulonephritis $(7.0 \%)$, and tubulointerstitial diseases $(5.6 \%)$. Moreover, their study revealed that independent factors associated with eGFR $<30 \mathrm{~mL} / \mathrm{min} / 1.73 \mathrm{~m}^{2}$ at presentation were: HIV (odds ratio $2.4,95 \%$ CI 1.3-4.2; $P=0.004$ ) and hypertension (odds ratio, 95\% CI 1.3-4.2; $P=0.007)$. CKD patients have increased risk of CVD, due to increased prevalence of hypertension, dyslipidemia, and diabetes. The key features of dyslipidemia in mild and moderate CKD patients are elevated triglycerides and lipoprotein(a), lower HDL-C, with normal (or low) total cholesterol, and normal (or low) LDL-C. ${ }^{55}$ Therefore, assessment of renal function constitutes an important part of the management of dyslipidemia with HIV. However, in the future, the clinical impact and hence the requirement for more research in the area of CKD with HIV and retroviral therapy will likely increase, due to aging and continued antiretroviral exposure of the HIV-positive population.

\section{Hypothyroidism and HIV}

Patients infected with HIV have a higher prevalence of thyroid dysfunction when compared with the general population. In view of the fact that hypothyroidism is associated with hyperlipidemia, the focus of this section is on the prevalence of hypothyroidism with HIV. Importantly, ART can complicate thyroid function through drug interactions and the immune reconstitution inflammatory syndrome. ${ }^{56}$ The prevalence of hypothyroidism in HIV patients in France was found to be around 16\%, and low CD4 cell counts and administration of stavudine were risk factors. ${ }^{57}$ While in Thai patients, the

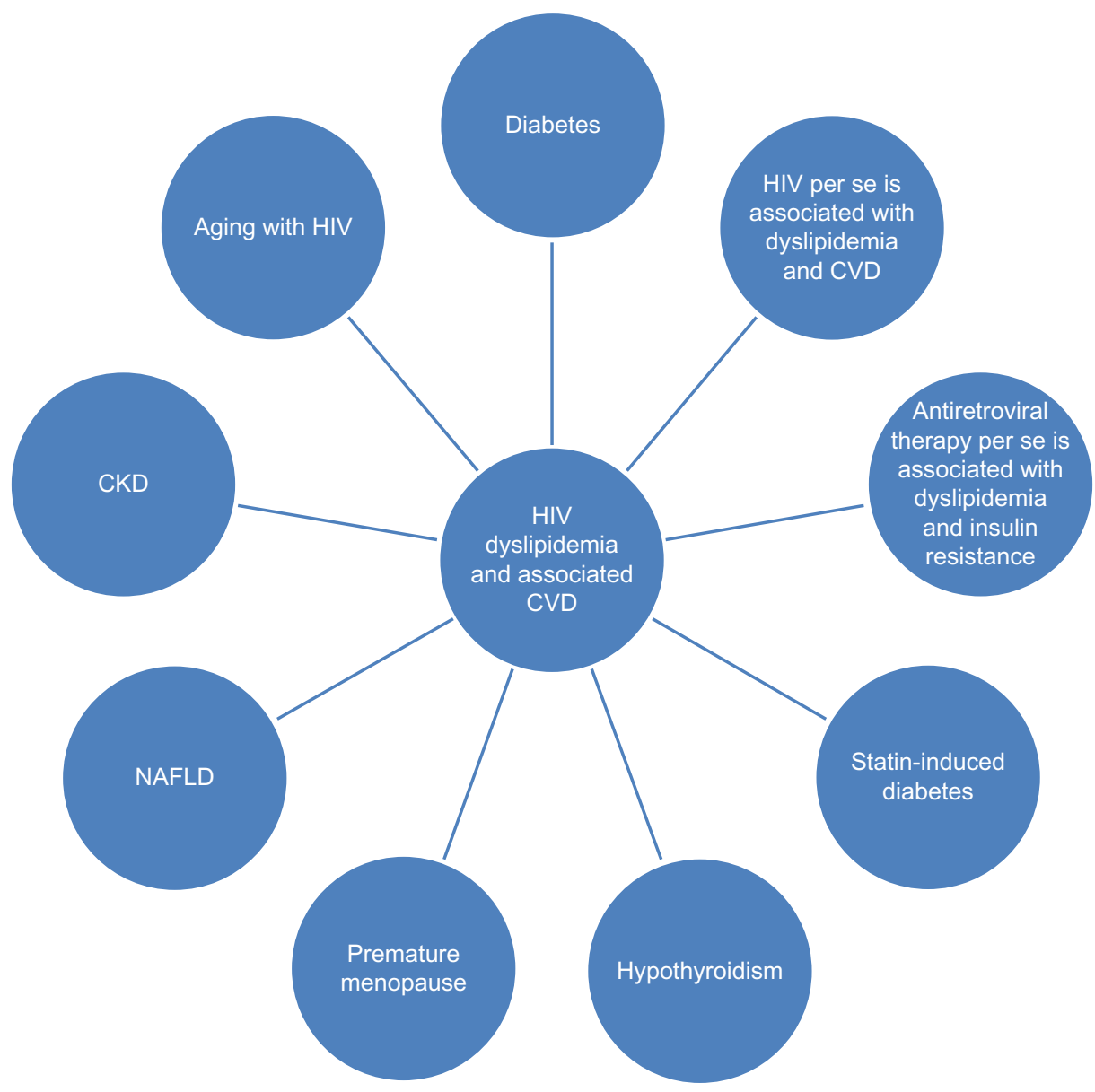

Figure I Illustration of different potential factors that lead hyperlipidemia with HIV and associated increase in risk of CVD.

Abbreviations: HIV, human immunodeficiency virus; CVD, cardiovascular disease; CKD, chronic kidney disease; NAFLD, nonalcoholic fatty liver disease. 
prevalence is $13.5 \%$, it is $15.5 \%$ in Colombia. ${ }^{58,59}$ Interestingly, a study from the US showed that the prevalence of abnormal thyroid function was around $12.4 \%$, while the prevalence of hypothyroidism was 7\% in Egypt. ${ }^{60,61}$ Therefore, screening for thyroid function should be part of the management of dyslipidemia with HIV and HIV treatment.

\section{Early menopause}

Menopause in the general population is associated with a threefold increase of risk of ischemic heart disease. Menopause is also associated with a high risk of atherosclerosis, dyslipidemia, insulin resistance, and thrombotic tendency. In a multicenter Italian surveillance study based on an anonymous questionnaire completed by 585 HIV-positive women aged 18 years or older, 352 women 45 years or younger were included in the analysis. Among the 352 patients 45 years or younger, 27 reported menopause for a prevalence of $7.7 \%$. Among the 173 women 40 years or younger, nine reported amenorrhea in the previous 12 months for a $5.2 \%$ prevalence. This last proportion was more than twofold greater than the one observed in the HIV-negative Italian population. The HIV-infected cohort was about equivalent to that in the general Italian population $(7.7 \%$ versus $7.1 \%)$. However, HIV-infected women had a greater prevalence of menopause at 40 years or younger than women in the population at large (5.2\% versus $1.8 \%) .{ }^{62} \mathrm{~A}$ review by Kojic et al suggested that the mean age of menopause for menopausal women living with HIV is likely to be 47-48 years, while for non-HIV women the mean age of menopause is around 51 years. ${ }^{63}$ Women living with HIV have multiple, potentially additive factors

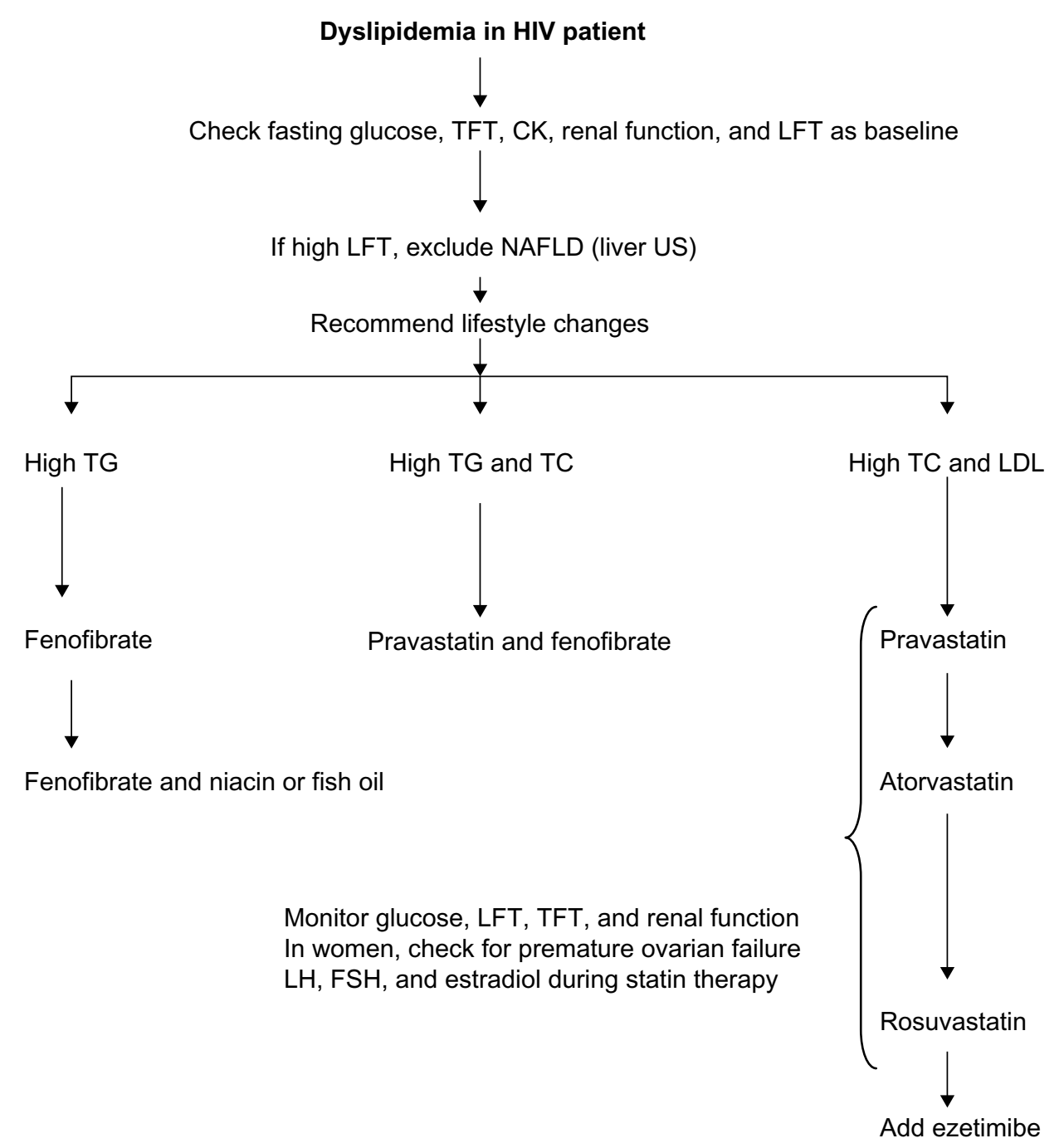

Figure 2 Illustration showing possible summary of current guidelines for the management of HIV dyslipidemia. Aging populations will need special consideration with regard to adjustment for lipid-lowering medication.

Abbreviations: HIV, human immunodeficiency virus; TFT, thyroid-function test; CK, creatine kinase; LFT, liver-function test; NAFLD, nonalcoholic fatty liver disease; US, ultrasonography; TG, triglyceride; TC, total cholesterol; LDL, low-density lipid; LH, luteinizing hormone; FSH, follicle-stimulating hormone. 
that predispose them to metabolic complications, including osteoporosis, lipid and glucose disturbances, and cardiovascular risk. ${ }^{63,64}$ These factors include the consequences of HIV itself, impact of ART, loss of the protective effects of estrogen in menopausal women, and adverse effects of highly active antiretroviral therapy (HAART). ${ }^{65,66}$

Statin therapy is useful in hyperlipidemic postmenopausal women. Statins can help maintain or increase bone mass of hypercholesterolemic menopausal women through promoting bone synthesis. ${ }^{67}$ In their population-based case-control study, Fournier et al found that statins could potentially attenuate the increased risk of venous thromboembolism associated with hormonal therapy combinations of oral estrogens and progestogens. ${ }^{6}{ }^{\text {Studies are needed to confirm }}$ whether these factors are clinically significant and for better understanding of the possible interactions between HIV and hormones and how these influence disease progression and treatment. Therefore, screening for early menopause in women with HIV should be part of the management of dyslipidemia with HIV and HIV treatment.

\section{Aging with HIV}

One important feature of the success of ART is that individuals with HIV live longer. In several studies, comorbidities like diabetes, dyslipidemia, CKD, hypertension, and CVD in HIV patients increased with age. ${ }^{69}$ This will lead to a significant burden in health resources in the near future unless extensive research is carried in order to develop the best health strategies to tackle such an epidemic.

\section{Solutions for hyperlipidemia in HIV patients}

The management of hyperlipidemia in HIV patients can be difficult. However, it is always recommended that lifestyle modifications in terms of weight reduction and calorie restriction are important part in the management of this type of difficult hyperlipidemia. Therefore, the majority of patients with HIV dyslipidemia may require lipid-lowering therapy. Controlled clinical trials and clinical experience have shown the benefit of statins as treatment for CVD, familial hypercholesterolemia, and dyslipidemia with diabetes. ${ }^{70}$ In addition, recent large clinical trials have further demonstrated the clinical benefits and safety of statins in patients with a wide range of high risks for CVD and safety of statins as monotherapy or in combination with other lipid-lowering medications. Interestingly, statins are safe and effective, and can improve liver tests and reduce cardiovascular morbidity in patients with
NAFLD. ${ }^{71-73}$ Different types of statins are available to lower plasma lipids to guideline levels in patients with HIV, but all differ in their pharmacokinetic properties, drug-interaction profiles, and risk of myotoxicity. Table 2 provides a summary of the effects of different statins and other lipid-lowering medication. ${ }^{15,17,74-110}$

\section{Conclusion}

The dyslipidemia in patients with HIV is unique, due to 1) the fact that HIV per se and treatment of HIV may induce it, 2) the interaction between HIV treatment and statins, and 3) HIV dyslipidemia may be related to HIV or HIV treatment-induced conditions like NAFLD, hypothyroidism, early menopause, diabetes, and CKD (Figure 1). The aging population of HIV patients will represent a serious challenge in terms of the management of dyslipidemia. Most guidelines recommend the use of rosuvastatin, atorvastatin, and pravastatin. Statin-unresponsive HIV dyslipidemia can be treated with the addition of ezetimibe, fenofibrate, fish oil, and niacin. Figure 2 illustrates the need to monitor glucose, liver, renal, and thyroid function. In women, it is important to manage issues related to premature menopause. We recommend that hyperlipidemia needs be managed in specialized clinics, and future research about the aging HIV population is needed.

\section{Disclosure}

The authors report no conflicts of interest in this work.

\section{References}

1. Bittar R, Giral P, Aslangul E, et al. Determinants of low-density lipoprotein particle diameter during antiretroviral therapy including protease inhibitors in HIV-1-infected patients. Antivir Ther. 2012;17(5): 855-860.

2. Grinspoon S, Carr A. Cardiovascular risk and body-fat abnormalities in HIV-infected adults. N Engl J Med. 2005;352(1):48-62.

3. Lo J, Grinspoon S. Cardiovascular disease in HIV-infected patients: does HIV infection in and of itself increase cardiovascular risk? Curr Opin HIV AIDS. 2008;3(3):207-213.

4. Dubé MP, Parker RA, Tebas P, et al. Glucose metabolism, lipid, and body fat changes in antiretroviral-naive subjects randomized to nelfinavir or efavirenz plus dual nucleosides. AIDS. 2005;19(16): 1807-1818.

5. Mothe B, Perez I, Domingo P, et al. HIV-1 infection in subjects older than 70: a multicenter cross-sectional assessment in Catalonia, Spain. Curr HIV Res. 2009;7(6):597-600.

6. Hejazi N, Rajikan R, Choong CL, Sahar S. Metabolic abnormalities in adult HIV infected population on antiretroviral medication in Malaysia: a cross-sectional survey. BMC Public Health. 2013;13:758.

7. Zou W, Berglund L. HIV and highly active antiretroviral therapy: dyslipidemia, metabolic aberrations, and cardiovascular risk. Prev Cardiol. 2007;10(2):96-103.

8. Mallewa JE, Higgins SP, Garbett S, Saxena N, Vilar FJ. Cardiovascular disease risk management in HIV patients, experiences from Greater Manchester. Int J STD AIDS. 2009;20(6):425-426. 
9. Calza L, Manfredi R, Chiodo F. Dyslipidaemia associated with antiretroviral therapy in HIV-infected patients. J Antimicrob Chemother. 2004;53(1):10-14.

10. Hruz PW, Murata H, Mueckler M. Adverse metabolic consequences of HIV protease inhibitor therapy: the search for a central mechanism. Am J Physiol Endocrinol Metab. 2001;280(4):E549-E553.

11. Fauvel J, Bonnet E, Ruidavets JB, et al. An interaction between Apo $\mathrm{C}$-III variants and protease inhibitors contributes to high triglyceride/low HDL levels in treated HIV patients. AIDS. 2001;15(18):2397-2406.

12. Viganò A, Aldrovandi GM, Giacomet V, et al. Improvement in dyslipidaemia after switching stavudine to tenofovir and replacing protease inhibitors with efavirenz in HIV-infected children. Antivir Ther. 2005;10(8):917-924.

13. D:A:D Study Group, Sabin CA, Worm SW, et al. Use of nucleoside reverse transcriptase inhibitors and risk of myocardial infarction in HIV-infected patients enrolled in the D:A:D study: a multi-cohort collaboration. Lancet. 2008;371(9622):1417-1426.

14. Bernal E, Masiá M, Padilla S, Gutiérrez F. High-density lipoprotein cholesterol in HIV-infected patients: evidence for an association with HIV-1 viral load, antiretroviral therapy status, and regimen composition. AIDS Patient Care STDS. 2008;22(7):569-575.

15. Penzak SR, Chuck SK, Stajich GV. Safety and efficacy of HMG-CoA reductase inhibitors for treatment of hyperlipidemia in patients with HIV infection. Pharmacotherapy. 2000;20(9):1066-1071.

16. Grinspoon SK, Grunfeld C, Kotler DP, et al. State of the science conference: Initiative to decrease cardiovascular risk and increase quality of care for patients living with HIV/AIDS: executive summary. Circulation. 2008;118(2):198-210.

17. Chu C, Umanski G, Blank A, Meissner P, Grossberg R, Selwyn PA. Comorbidity-related treatment outcomes among HIV-infected adults in the Bronx, NY. J Urban Health. 2011;88(3):507-516.

18. Kamin D, Hadigan C. Hyperlipidemia in children with HIV infection: an emerging problem. Expert Rev Cardiovasc Ther. 2003;1(1):143-150.

19. Miller TI, Borkowsky W, DiMeglio LA, et al. Metabolic abnormalities and viral replication are associated with biomarkers of vascular dysfunction in HIV-infected children. HIV Med. 2012;13(5):264-275.

20. Patel K, Wang J, Jacobson DL, et al. Aggregate risk of cardiovascular disease among adolescents perinatally infected with the human immunodeficiency virus. Circulation. 2014;129(11):1204-1212.

21. Echeverría P, Domingo P, Llibre JM, et al. Prevalence of ischemic heart disease and management of coronary risk in daily clinical practice: results from a Mediterranean cohort of HIV-infected patients. Biomed Res Int. 2014;2014:823058.

22. Worm SW, De Wit S, Weber R, et al. Diabetes mellitus, preexisting coronary heart disease, and the risk of subsequent coronary heart disease events in patients infected with human immunodeficiency virus: the Data Collection on Adverse Events of Anti-HIV Drugs (D:A:D Study). Circulation. 2009;119(6):805-811.

23. Worm SW, Friis-Møller N, Bruyand M, et al. High prevalence of the metabolic syndrome in HIV-infected patients: impact of different definitions of the metabolic syndrome. AIDS. 2010;24(3):427-435.

24. Triant VA, Lee H, Hadigan C, Grinspoon SK. Increased acute myocardial infarction rates and cardiovascular risk factors among patients with human immunodeficiency virus disease. J Clin Endocrinol Metab. 2007;92(7):2506-2512.

25. DAD Study Group, Friis-Møller N, Reiss P, et al. Class of antiretroviral drugs and the risk of myocardial infarction. NEngl J Med. 2007;356(17): 1723-1735.

26. Menezes de Pádua CA, Moura CS. Availability of data on adverse reactions to antiretroviral drugs in medical charts according to the Naranjo algorithm: an example of a Brazilian historical cohort. Clin Drug Investig. 2014;34(6):395-402.

27. Kagaruki GB, Mayige MT, Ngadaya ES, et al. Magnitude and risk factors of non-communicable diseases among people living with HIV in Tanzania: a cross sectional study from Mbeya and Dar es Salaam regions. BMC Public Health. 2014;14:904.
28. Ngala RA, Fianko K. Dyslipidaemia and dysglycaemia in HIV-infected patients on highly active anti-retroviral therapy in Kumasi Metropolis. Afr Health Sci. 2013;13(4):1107-1116.

29. Jantarapakde J, Phanuphak N, Chaturawit C, et al. Prevalence of metabolic syndrome among antiretroviral-naive and antiretroviralexperienced HIV-1 infected Thai adults. AIDS Patient Care STDS. 2014;28(7):331-340.

30. Tesfaye DY, Kinde S, Medhin G, et al. Burden of metabolic syndrome among HIV-infected patients in Southern Ethiopia. Diabetes Metab Syndr. 2014;8(2):102-107.

31. Paula AA, Schechter M, Tuboi SH, et al. Continuous increase of cardiovascular diseases, diabetes, and non-HIV related cancers as causes of death in HIV-infected individuals in Brazil: an analysis of nationwide data. PLoS One. 2014;9(4):e94636.

32. Tripathi A, Jerrell JM, Liese AD, et al. Association of clinical and therapeutic factors with incident dyslipidemia in a cohort of human immunodeficiency virus-infected and non-infected adults: 1994-2011. Metab Syndr Relat Disord. 2013;11(6):417-426.

33. Ledergerber B, Furrer H, Rickenbach M, et al. Factors associated with the incidence of type 2 diabetes mellitus in HIV-infected participants in the Swiss HIV Cohort Study. Clin Infect Dis. 2007;45(1):111-119.

34. de Waal R, Cohen K, Maartens G. Systematic review of antiretroviralassociated lipodystrophy: lipoatrophy, but not central fat gain, is an antiretroviral adverse drug reaction. PLoS One. 2013;8(5):e63623.

35. Kotler DP. HIV lipodystrophy etiology and pathogenesis. Body composition and metabolic alterations: etiology and pathogenesis. AIDS Read. 2003;13(Suppl 4):S5-S9.

36. Lemoine M, Serfaty L, Capeau J. From nonalcoholic fatty liver to nonalcoholic steatohepatitis and cirrhosis in HIV-infected patients: diagnosis and management. Curr Opin Infect Dis. 2012;25(1):10-16.

37. Arendt BM, Mohammed SS, Ma DW, et al. Non-alcoholic fatty liver disease in HIV infection associated with altered hepatic fatty acid composition. Curr HIV Res. 2011;9(2):128-135.

38. Crum-Cianflone N, Krause D, Wessman D, et al. Fatty liver disease is associated with underlying cardiovascular disease in HIV-infected persons. HIV Med. 2011;12(8):463-471.

39. Ahmed MH, Byrne CD. Modulation of sterol regulatory element binding proteins (SREBPs) as potential treatments for non-alcoholic fatty liver disease (NAFLD). Drug Discov Today. 2007;12(17-18):740-747.

40. Ahmed MH, Byrne CD. Current treatment of non-alcoholic fatty liver disease. Diabetes Obes Metab. 2009;11(3):188-195.

41. Price JC, Seaberg EC, Latanich R, et al. Risk factors for fatty liver in the Multicenter AIDS Cohort Study. Am J Gastroenterol. 2014;109(5): 695-704.

42. Nishijima T, Gatanaga H, Shimbo T, et al. Traditional but not HIVrelated factors are associated with nonalcoholic fatty liver disease in Asian patients with HIV-1 infection. PLoS One. 2014;9(1):e87596.

43. Sterling RK, Smith PG, Brunt EM. Hepatic steatosis in human immunodeficiency virus: a prospective study in patients without viral hepatitis, diabetes, or alcohol abuse. J Clin Gastroenterol. 2013;47(2): $182-187$.

44. Machado MV, Oliveira AG, Cortez-Pinto H. Hepatic steatosis in patients coinfected with human immunodeficiency virus/hepatitis $\mathrm{C}$ virus: a meta-analysis of the risk factors. Hepatology. 2010;52(1):71-78.

45. Bani-Sadr F, Barange K, Daoud F, et al. Persistently normal alanine aminotransferase levels in HIV/HCV-coinfected patients: the role of steatosis. HIV Med. 2009;10(7):417-421.

46. Sattar N, Preiss D, Murray HM, et al. Statins and risk of incident diabetes: a collaborative meta-analysis of randomised statin trials. Lancet. 2010;375(9716):735-742.

47. Preiss D, Seshasai SR, Welsh P, et al. Risk of incident diabetes with intensive-dose compared with moderate-dose statin therapy: a metaanalysis. JAMA. 2011;305(24):2556-2564.

48. Culver AL, Ockene IS, Balasubramanian R, et al. Statin use and risk of diabetes mellitus in postmenopausal women in the Women's Health Initiative. Arch Intern Med. 2012;172(2):144-152. 
49. Athyros VG, Mikhailidis DP. Pharmacotherapy: statins and new-onset diabetes mellitus - a matter for debate. Nat Rev Endocrinol. 2012;8(3): $133-134$

50. Athyros VG, Tziomalos K, Karagiannis A, Mikhailidis DP. Lipid-lowering agents and new onset diabetes mellitus. Expert Opin Pharmacother. 2010;11(12):1965-1970.

51. Hsieh MH, Lu PL, Kuo MC, et al. Prevalence of and associated factors with chronic kidney disease in human immunodeficiency virus-infected patients in Taiwan. J Microbiol Immunol Infect. Epub October 7, 2013.

52. Rasch MG, Engsig FN, Feldt-Rasmussen B, et al. Renal function and incidence of chronic kidney disease in HIV patients: a Danish cohort study. Scand J Infect Dis. 2012;44(9):689-696.

53. Wyatt CM. The kidney in HIV infection: beyond HIV-associated nephropathy. Top Antivir Med. 2012;20(3):106-110.

54. Madala ND, Thusi GP, Assounga AG, Naicker S. Characteristics of South African patients presenting with kidney disease in rural KwaZulu-Natal: a cross sectional study. BMC Nephrol. 2014;15:61.

55. Ahmed MH, Khalil AA. Ezetimibe as a potential treatment for dyslipidemia associated with chronic renal failure and renal transplant. Saudi J Kidney Dis Transpl. 2010;21(6):1021-1029.

56. Parsa AA, Bhangoo A. HIV and thyroid dysfunction. Rev Endocr Metab Disord. 2013;14(2):127-131.

57. Beltran S, Lescure FX, Desailloud R, et al. Increased prevalence of hypothyroidism among human immunodeficiency virus-infected patients: a need for screening. Clin Infect Dis. 2003;37(4):579-583.

58. Gómez QC, Vesga GJ, Lowenstein De ME, et al. [Mass screening for hypothyroidism in a cohort of HIV infected patients in a Bogotá hospital, Colombia]. Rev Chilena Infectol. 2011;28(1):59-63. Spanish.

59. Ketsamathi C, Jongjaroenprasert W, Chailurkit LO, Udomsubpayakul U, Kiertiburanakul S. Prevalence of thyroid dysfunction in Thai HIVinfected patients. Curr HIV Res. 2006;4(4):463-467.

60. Wiener M, Lo Y, Klein RS. Abnormal thyroid function in older men with or at risk for HIV infection. HIV Med. 2008;9(7):544-549.

61. Noureldeen A, Qusti SY, Khoja GM. Thyroid function in newly diagnosed HIV-infected patients. Toxicol Ind Health. 2014;30(10): 919-925.

62. de Pommerol M, Hessamfar M, Lawson-Ayayi S, et al. Menopause and HIV infection: age at onset and associated factors, ANRS CO3 Aquitaine cohort. Int J STD AIDS. 2011;22(2):67-72.

63. Kojic EM, Wang CC, Cu-Uvin S. HIV and menopause: a review. $J$ Womens Health (Larchmt). 2007;16(10):1402-1411.

64. Yin MT, Shu A, Zhang CA, et al. Trabecular and cortical microarchitecture in postmenopausal HIV-infected women. Calcif Tissue Int. 2013;92(6):557-565

65. Ferreira CE, Pinto-Neto AM, Conde DM, Costa-Paiva L, Morais SS, Magalhães J. Menopause symptoms in women infected with HIV: prevalence and associated factors. Gynecol Endocrinol. 2007;23(4): 198-205.

66. Loutfy MR, Sonnenberg-Schwan U, Margolese S, Sherr L. A review of reproductive health research, guidelines and related gaps for women living with HIV. AIDS Care. 2013;25(6):657-666.

67. Ibrahim N', Mohamed N, Shuid AN. Update on statins: hope for osteoporotic fracture healing treatment. Curr Drug Targets. 2013;14(13): 1524-1532.

68. Fournier JP, Duijnhoven RG, Renoux C, Dell'Aniello S, Klungel OH, Suissa S. Concurrent use of statins and hormone therapy and risk of venous thromboembolism in postmenopausal women: a populationbased case-control study. Menopause. 2014;21(9):1023-1026.

69. Cardoso SW, Torres TS, Santini-Oliveira M, Marins LM, Veloso VG, Grinsztejn B. Aging with HIV: a practical review. Braz J Infect Dis. 2013;17(4):464-479.

70. Ahmed MH, Hamad MA, Routh C, Connolly V. Statins as potential treatment for cholesterol gallstones: an attempt to understand the underlying mechanism of actions. Expert Opin Pharmacother. 2011;12(17): 2673-2681.
71. Athyros VG, Tziomalos K, Gossios TD, et al. Safety and efficacy of long-term statin treatment for cardiovascular events in patients with coronary heart disease and abnormal liver tests in the Greek Atorvastatin and Coronary Heart Disease Evaluation (GREACE) Study: a post-hoc analysis. Lancet. 2010;376(9756):1916-1922.

72. Athyros VG, Tziomalos K, Daskalopoulos GN, Karagiannis A, Mikhailidis DP. Statin-based treatment for cardiovascular risk and non-alcoholic fatty liver disease. Killing two birds with one stone? Ann Med. 2011;43(3):167-171.

73. Athyros VG, Mikhailidis DP, Didangelos TP, et al. Effect of multifactorial treatment on non-alcoholic fatty liver disease in metabolic syndrome: a randomised study. Curr Med Res Opin. 2006;22(5):873-883.

74. Williams D, Feely J. Pharmacokinetic-pharmacodynamic drug interactions with HMG-CoA reductase inhibitors. Clin Pharmacokinet. 2002;41(5):343-370.

75. Penzak SR, Chuck SK. Management of protease inhibitor-associated hyperlipidemia. Am J Cardiovasc Drugs. 2002;2(2):91-106.

76. Gerber JG, Rosenkranz SL, Fichtenbaum CJ, et al. Effect of efavirenz on the pharmacokinetics of simvastatin, atorvastatin, and pravastatin: results of AIDS Clinical Trials Group 5108 Study. J Acquir Immune Defic Syndr. 2005;39(3):307-312.

77. Melroe NH, Kopaczewski J, Henry K, Huebsch J. Intervention for hyperlipidemia associated with protease inhibitors. J Assoc Nurses AIDS Care. 1999;10(4):55-69.

78. Dube MP, Stein JH, Aberg JA, et al. Guidelines for the evaluation and management of dyslipidemia in human immunodeficiency virus (HIV)-infected adults receiving antiretroviral therapy: recommendations of the HIV Medical Association of the Infectious Disease Society of America and the Adult AIDS Clinical Trials Group. Clin Infect Dis. 2003;37(5):613-627.

79. Schambelan M, Benson CA, Carr A, et al. Management of metabolic complications associated with antiretroviral therapy for HIV-1 infection: recommendations of an International AIDS Society-USA panel. J Acquir Immune Defic Syndr. 2002;31(3):257-275.

80. Lo J. Dyslipidemia and lipid management in HIV-infected patients. Curr Opin Endocrinol Diabetes Obes. 2011;18(2):144-147.

81. Soler A, Deig E, Guil J, Rodríguez-Martin M, Guelar A, Pedrol E. [Effectiveness and tolerance of atorvastatin for antiretroviral therapysecondary dyslipemia]. Med Clin (Barc). 2006;127(7):250-252. Spanish.

82. Jacobson TA. Comparative pharmacokinetic interaction profiles of pravastatin, simvastatin, and atorvastatin when coadministered with cytochrome P450 inhibitors. Am J Cardiol. 2004;94(9): 1140-1146.

83. Bonnet F, Aurillac-Lavignolle V, Breilh D, et al. Pravastatin in HIVinfected patients treated with protease inhibitors: a placebo-controlled randomized study. HIV Clin Trials. 2007;8(1):53-60.

84. Stein JH, Merwood MA, Bellehumeur JL, et al. Effects of pravastatin on lipoproteins and endothelial function in patients receiving human immunodeficiency virus protease inhibitors. Am Heart J. 2004; 147(4):E18.

85. Aberg JA, Zackin RA, Brobst SW, et al. A randomized trial of the efficacy and safety of fenofibrate versus pravastatin in HIV-infected subjects with lipid abnormalities: AIDS Clinical Trials Group Study 5087. AIDS Res Hum Retroviruses. 2005;21(9):757-767.

86. Calza L, Colangeli V, Manfredi R, et al. Rosuvastatin for the treatment of hyperlipidaemia in HIV-infected patients receiving protease inhibitors: a pilot study. AIDS. 2005;19(10):1103-1105.

87. Ahmed MH. Rosuvastatin as treatment for non alcoholic steatohepatitis (NASH) and highly active antiretroviral therapy (HAART)dyslipidaemia: new treatment for global dangers. Med Hypotheses. 2006;66(2):440-441.

88. Calza L, Manfredi R, Colangeli V, Pocaterra D, Pavoni M, Chiodo F. Rosuvastatin, pravastatin, and atorvastatin for the treatment of hypercholesterolaemia in HIV-infected patients receiving protease inhibitors. Curr HIV Res. 2008;6(6):572-578. 
89. Aslangul E, Assoumou L, Bittar R, et al. Rosuvastatin versus pravastatin in dyslipidemic HIV-1-infected patients receiving protease inhibitors: a randomized trial. AIDS. 2010;24(1):77-83.

90. Bottaro EG, Caravello O, Scapellato PG, et al. [Rosuvastatin for the treatment of dyslipidemia in HIV-infected patients receiving highly active antiretroviral therapy. Preliminary experience]. Enferm Infecc Microbiol Clin. 2008;26(6):325-329. Spanish.

91. Singh S, Willig JH, Mugavero MJ, et al. Comparative effectiveness and toxicity of statins among HIV-infected patients. Clin Infect Dis. 2011;52(3):387-395.

92. Benesic A, Zilly M, Kluge F, et al. Lipid lowering therapy with fluvastatin and pravastatin in patients with HIV infection and antiretroviral therapy: comparison of efficacy and interaction with indinavir. Infection. 2004;32(4):229-233.

93. Calza L, Manfredi R, Chiodo F. Statins and fibrates for the treatment of hyperlipidaemia in HIV-infected patients receiving HAART. AIDS. 2003;17(6):851-859.

94. Wohl DA, Waters D, Simpson RJ Jr, et al. Ezetimibe alone reduces low-density lipoprotein cholesterol in HIV-infected patients receiving combination antiretroviral therapy. Clin Infect Dis. 2008;47(8): 1105-1108

95. Negredo E, Molto J, Puig J, et al. Ezetimibe, a promising lipidlowering agent for the treatment of dyslipidaemia in HIV-infected patients with poor response to statins. AIDS. 2006;20(17): 2159-2164.

96. Chow D, Chen H, Glesby MJ, et al. Short-term ezetimibe is well tolerated and effective in combination with statin therapy to treat elevated LDL cholesterol in HIV-infected patients. AIDS. 2009;23(16): 2133-2141.

97. Berg-Wolf MV, Klibanov OM, Gaughan JP, Tedaldi EM. Ezetimibe combined with low-dose statin effectively lowers LDL in protease inhibitor treated patients. AIDS Patient Care STDS. Epub May 7, 2008.

98. Chastain LM, Bain AM, Edwards KL, Bedimo R, Busti AJ. A retrospective study of the lipid-lowering efficacy and safety of ezetimibe added to hydroxy methylglutaryl coenzyme A reductase therapy in HIV-infected patients with hyperlipidemia. J Clin Lipidol. 2007;1(6):634-639.

99. Bennett MT, Johns KW, Bondy GP. Ezetimibe is effective when added to maximally tolerated lipid lowering therapy in patients with HIV. Lipids Health Dis. 2007;6:15.
100. Samineni D, Fichtenbaum CJ. Fenofibrate in the treatment of dyslipidemia associated with HIV infection. Expert Opin Drug Metab Toxicol. 2010;6(8):995-1004.

101. Badiou S, Merle De Boever C, Dupuy AM, Baillat V, Cristol JP, Reynes J. Fenofibrate improves the atherogenic lipid profile and enhances LDL resistance to oxidation in HIV-positive adults. Atherosclerosis. 2004;172(2):273-279.

102. Thomas JC, Lopes-Virella MF, Del Bene VE, et al. Use of fenofibrate in the management of protease inhibitor-associated lipid abnormalities. Pharmacotherapy. 2000;20(6):727-734.

103. Rao A, D'Amico S, Balasubramanyam A, Maldonado M. Fenofibrate is effective in treating hypertriglyceridemia associated with HIV lipodystrophy. Am J Med Sci. 2004;327(6):315-318.

104. Fichtenbaum CJ, Yeh TM, Evans SR, Aberg JA. Treatment with pravastatin and fenofibrate improves atherogenic lipid profiles but not inflammatory markers in ACTG 5087. J Clin Lipidol. 2010;4(4): 279-287.

105. Balasubramanyam A, Coraza I, Smith EO, et al. Combination of niacin and fenofibrate with lifestyle changes improves dyslipidemia and hypoadiponectinemia in HIV patients on antiretroviral therapy: results of "Heart Positive," a randomized, controlled trial. J Clin Endocrinol Metab. 2011;96(7):2236-2247.

106. Gerber JG, Kitch DW, Fichtenbaum CJ, et al. Fish oil and fenofibrate for the treatment of hypertriglyceridemia in HIV-infected subjects on antiretroviral therapy: results of ACTG A5186. JAcquir Immune Defic Syndr. 2008;47(4):459-466.

107. Samson SL, Pownall HJ, Scott LW, et al. Heart Positive: design of a randomized controlled clinical trial of intensive lifestyle intervention, niacin and fenofibrate for HIV lipodystrophy/dyslipidemia. Contemp Clin Trials. 2006;27(6):518-530.

108. Souza SA, Chow DC, Walsh EJ, Ford S 3rd, Shikuma C. Pilot study on the safety and tolerability of extended release niacin for HIV-infected patients with hypertriglyceridemia. Hawaii Med J. 2010;69(5):122-125.

109. Gerber MT, Mondy KE, Yarasheski KE, et al. Niacin in HIV-infected individuals with hyperlipidemia receiving potent antiretroviral therapy. Clin Infect Dis. 2004;39(3):419-425.

110. Dubé MP, Wu JW, Aberg JA, et al. Safety and efficacy of extendedrelease niacin for the treatment of dyslipidaemia in patients with HIV infection: AIDS Clinical Trials Group Study A5148. Antivir Ther. 2006;11(8):1081-1089.
HIV/AIDS - Research and Palliative Care

\section{Publish your work in this journal}

HIV/AIDS - Research and Palliative Care is an international, peerreviewed open-access journal focusing on advances in research in HIV, its clinical progression and management options including antiviral treatment, palliative care and public healthcare policies to control viral spread. The journal welcomes original research, basic science,

\section{Dovepress}

clinical \& epidemiological studies, reviews \& evaluations, expert opinion \& commentary, case reports \& extended reports. The manuscript management system is completely online and includes a very quick and fair peer-review system. Visit http://www.dovepress.com/ testimonials.php to read real quotes from published authors. 